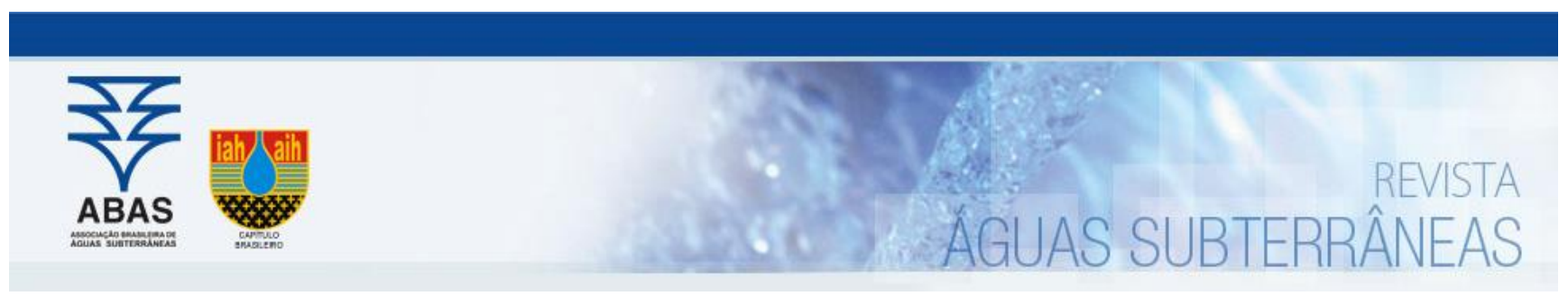

Artigos

\title{
Avaliação das características e impactos do etanol nas contaminações por combustíveis no Estado de São Paulo
}

\section{Assessment of the characteristics and ethanol impacts on fuel contaminations in São Paulo State}

\author{
Juliana Gardenalli de Freitas; Fernanda Campos de Oliveira1; Fernanda Scalon Sapojkin; Letícia Mina Umiji Morioka1; Mary \\ Ishimine Nishita1; Gabriella Ferraro1; Aline Machiavelli de Lima1 ${ }^{\circledR}$ \\ 1 Universidade Federal de São Paulo (UNIFESP), Diadema, SP
}

$\bowtie$ jgfreitas@unifesp.br, fernanda.oliveira@erm.com, f.sapojkin@gmail.com, mina morioka@hotmail.com, mary.nsht@gmail.com, gabferraro@gmail.com, alinemachiavel@gmail.com

Palavras-chave:

Gasolina.

Plumas.

Contaminação.

Postos de combustíveis.
Resumo

Postos de combustíveis são uma das principais fontes de contaminação de solos e águas subterrâneas, estando presente de forma distribuída por todo o Estado de São Paulo, principalmente nas áreas urbanas. Os principais contaminantes associados a essas fontes são hidrocarbonetos aromáticos (benzeno, tolueno, etilbenzeno e xilenos), hidrocarbonetos aromáticos policíclicos e etanol, utilizado por décadas como aditivo na gasolina e combustível. Essa pesquisa buscou avaliar as principais características e fatores condicionantes das contaminações de solo e água subterrânea provenientes dos postos de combustível no Estado de São Paulo. Baseado na análise de 516 áreas contaminadas foi observada baixa correlação da localização regional (geologia e pedologia) com as características da contaminação. Metade das áreas apresentaram plumas de benzeno menor que $29 \mathrm{~m}$, valor inferior ao observado em estudos nos Estados Unidos. A condutividade hidráulica se destacou como um fator condicionante para a extensão das plumas, assim como a ocorrência de processos de atenuação natural. A presença de etanol em concentrações elevadas (> $1000 \mathrm{mg} \mathrm{L}^{-1}$ ) apareceu associada a plumas de maiores extensões e maiores concentrações de hidrocarbonetos. No entanto, de forma geral as contaminações provocadas por postos de combustíveis apresentaram extensão relativamente pequena (percentil 90 e 75 menores que 73 e 43 m, respectivamente) e persistência limitada pela ocorrência de processos de atenuação natural.

\section{Abstract}

Fuel stations are an important source for soil and groundwater contamination, being commonly found in São Paulo State, particularly in urban areas. The main contaminants associated to these sources are aromatic hydrocarbons (benzene, toluene, ethylbenzene, and xylenes), polycyclic aromatic hydrocarbons and ethanol, used in Brazil for decades as a gasoline additive and a fuel itself. This research aimed to evaluate the main characteristics and controlling factors of soil and groundwater contamination associated to these sources. Based on the analysis of 516 contaminated sites there was no evident correlation between the regional location (geology and pedology) with the contamination characteristics. Half of the sites presented benzene plume lengths lower than $29 \mathrm{~m}$, less than observed in similar studies conducted in the US. Hydraulic conductivity was identified as a conditioning factor for plumes extension, as well as the occurrence of natural attenuation processes. Ethanol presence in high concentrations (>1000 mg L-1) was associated with longer benzene plumes and higher hydrocarbon concentrations. However, in general, the contamination associated to fuel stations in São Paulo State presented relatively small extension (90th and 75th percentiles lower than 73 and $43 \mathrm{~m}$, respectively) and persistence limited by natural attenuation processes.

\section{INTRODUÇÃO}

Em 2018, mais de 40 mil postos revendedores de combustíveis operavam no Brasil, sendo a maior parte concentrada na região sudeste, aproximadamente 39\% do total (ANP, 2019). O Estado de São Paulo possuía quase 9000 postos revendedores de combustíveis em 2018 e, em 2019, 4475 das áreas no cadastro de áreas contaminadas da Cetesb correspondiam a áreas 
com revenda e distribuição de combustíveis líquidos (ANP, 2019; CETESB, 2020). Nessas áreas, as contaminações de solos e águas subterrâneas podem estar associadas a vazamento dos tanques de armazenamento e demais instalações e/ou acidentes. A gasolina, um dos contaminantes dos postos de combustíveis, é constituída por centenas de substâncias, sendo as principais: benzeno, tolueno, etilbenzeno e os isômeros do xileno (BTEX), além dos hidrocarbonetos policíclicos aromáticos (HPAs), como o naftaleno e o antraceno. Dentre esses, destacase o benzeno por possuir maior mobilidade e toxicidade em relação aos demais, além de ser um composto carcinogênico para humanos (WHO, 1996). Além da gasolina, o óleo diesel também é um poluente comum em postos de combustíveis, contendo compostos de cadeias mais longas, incluindo os HPAs.

Devido a sua maior mobilidade, decorrente da maior solubilidade efetiva e menor potencial de sorção, o benzeno tende a gerar plumas dissolvidas de maior extensão em relação aos outros hidrocarbonetos (ATTEIA; GUILOTT, 2007; SEAGREN et al., 2002). A extensão dessas plumas é dependente de uma série de fatores, que controlam os processos de transporte e atenuação natural. Esses fatores podem estar relacionados a características da fonte (como duração do vazamento e volume derramado), do meio físico (como litologia, fração de carbono orgânico, geoquímica e velocidade de fluxo) e biótico (diversidade e densidade da microbiota) (LOGESHWARAN et al., 2018; MA et al., 2013; DEEB et al., 2002; SEAGREN et al., 2002). Levantamento realizado por Connor et al. (2015) baseado em plumas de benzeno em 165 áreas nos Estados Unidos indicou que, considerando um limite de $5 \mu \mathrm{g} \mathrm{L-1}$ para delimitar o comprimento das plumas de benzeno, a mediana do comprimento foi de aproximadamente $55 \mathrm{~m}$ e 90\% das áreas apresentavam plumas com comprimento até $130 \mathrm{~m}$.

Além dos combustíveis derivados de petróleo, no Brasil as contaminações associadas a postos de abastecimento também podem conter etanol, que é comercializado como etanol hidratado e como aditivo na gasolina (etanol anidro). O etanol passou a ser comercializado como combustível a partir de 1979 e sua comercialização ganhou notoriedade com a segunda fase do programa Proálcool, sendo que a primeira fase estava relacionada à produção de álcool como aditivo a gasolina (MICHELLON et al., 2008; BELICANTA et al. 2016). Na década de 70, houve um aumento de $300 \%$ na produção de etanol no Brasil bem como na utilização do etanol hidratado como combustível automotivo. Além do aumento na produção e utilização como combustível, seu teor foi elevado como aditivo na gasolina. Até 2014, o percentual de etanol anidro na gasolina utilizada no Brasil era de 20 a 25\%, passando para 27\% em 2015 (MAPA, 2015).

Apesar de apresentar baixa toxicidade e não possuir valor de intervenção, o etanol pode interferir nos processos de transporte e reações envolvendo hidrocarbonetos em subsuperfície (RAMA et al.; 2019; STEINER et al., 2018; ALVAREZ et al., 2002; CORSEUIL et al., 1998; DEEB et al., 2002; POWERS et al.,
2001). Isso pode acontecer pela alteração direta das propriedades dos hidrocarbonetos ou causando alterações no meio que impactam o destino dos hidrocarbonetos. Como exemplos de alteração direta nas propriedades, o etanol pode aumentar a solubilidade dos hidrocarbonetos por cosolvência e diminuir a tensão interfacial entre a gasolina e a água, tornando a fase oleosa mais móvel (FIRTH et al., 2014; POWERS et al., 2001; CORSEUIL et al., 2004). Por outro lado, o etanol tende a ser preferencialmente biodegradado, o que pode resultar em decréscimo das concentrações de oxigênio e nutrientes, dificultando a biodegradação dos componentes mais nocivos presentes na gasolina como os BTEX (FREITAS et al., 2011; MACKAY et al., 2006; ALVAREZ e HUNT, 2002; DEEB et al., 2002; CORSEUIL et al., 1998). O etanol é altamente hidrofílico e, portanto, quando ocorre um vazamento de gasolina com etanol ele tende a se separar da fase oleosa durante a infiltração na zona não-saturada. Essa separação pode diminuir os impactos do etanol na contaminação pela gasolina (FREITAS e BARKER, 2011). Assim, apesar de estudos indicarem potenciais efeitos do etanol no comportamento dos hidrocarbonetos, esses efeitos são complexos e extremamente dependentes das condições do meio.

O Estado de São Paulo tem sido pioneiro no Brasil no gerenciamento de áreas contaminadas no Brasil, com a atuação da Companhia Ambiental do Estado de São Paulo (CETESB) em relação a contaminação de solos e águas subterrâneas tendo início na década de 70 e sendo intensificada a partir da década de 90 (FERREIRA et al., 2020; ARAÚJO-MOURA e CAFFARO FILHO, 2015). Devido a isso, muitos dados de caracterização de áreas contaminadas por postos de abastecimento foram gerados ao longo dos anos.

Considerando a importância dos postos de combustíveis como fonte de contaminação e o uso por longo prazo do etanol como combustível no Brasil, essa pesquisa teve por objetivo analisar dados existentes sobre contaminação por combustíveis em subsuperfície no Estado de São Paulo, buscando avaliar e comparar com outros países as características das contaminações em fase dissolvida no estado, e identificar quais os principais parâmetros que interferem nessas contaminações. Também teve como objetivo avaliar como o uso de etanol por um longo período impacta o desenvolvimento da contaminação por hidrocarbonetos.

\section{METODOLOGIA}

\subsection{Coleta de dados}

Os dados referentes às contaminações foram coletados entre dezembro de 2015 e março de 2016, em relatórios de investigação ambiental de postos de combustíveis, dando vistas aos processos de contaminação de áreas contaminadas na CETESB. Os dados coletados foram organizados e tabulados em grupos de informação. Os grupos definidos para análise foram: informações relativas ao estabelecimento comercial; dados para a caracterização física do meio; histórico da área; e dados relativos à investigação ambiental (Tabela 1). Para cada item 
citado, diversas informações foram levantadas nos relatórios de investigação ambiental consultados.

Em relação aos contaminantes, foram levantados os dados sobre as concentrações máximas dos compostos: benzeno (B), toIueno $(T)$, etilbenzeno $(E)$, xilenos $(X)$, antraceno $(A)$, naftaleno (N) e etanol (EtOH) ao longo da série histórica de investigação. Nas amostras com máximas concentrações de etanol, foram consideradas as concentrações dos hidrocarbonetos para ava- liação de potenciais efeitos de cosolvência. Avaliou-se também a máxima extensão longitudinal, transversal e vertical das plumas de benzeno, delimitadas pela concentração de $5 \mu \mathrm{g} \mathrm{L}^{-1}$, e de etanol, definidas pela detecção do composto acima do limite de quantificação. Quando não informada no relatório, a data do vazamento foi estimada a partir da data de início da investigação.

Tabela 1 - Síntese dos tipos de dados coletados dos relatórios de investigação

\begin{tabular}{|c|c|c|c|c|}
\hline $\begin{array}{l}\text { Estabelecimento } \\
\text { comercial }\end{array}$ & $\begin{array}{c}\text { Caracterização física do } \\
\text { meio }\end{array}$ & Histórico do local & $\begin{array}{l}\text { Investigação } \\
\text { ambiental }\end{array}$ & Contaminantes \\
\hline $\mathrm{N}^{\circ}$ do processo & Geologia & Data do vazamento & $\begin{array}{l}\text { Número de poços } \\
\text { instalados }\end{array}$ & $\begin{array}{c}\text { Comprimentos das } \\
\text { plumas de benzeno } \\
\text { e etanol }\left(\mathrm{L}_{\mathrm{i}}\right)\end{array}$ \\
\hline Identificação & Pedologia & $\begin{array}{l}\text { Combustíveis arma- } \\
\text { zenados nos tanques }\end{array}$ & $\begin{array}{c}\text { Investigação para } \\
\text { etanol }\end{array}$ & $\begin{array}{l}\text { Concentrações } \\
\text { máximas }\left(\mathrm{C}_{\mathrm{i}}\right)\end{array}$ \\
\hline Localização & Granulometria & $\begin{array}{l}\text { Tanques antigos, } \\
\text { removidos ou não }\end{array}$ & $\begin{array}{l}\text { Fonte secundária } \\
\text { de contaminação }\end{array}$ & \\
\hline $\begin{array}{l}\text { Tempo de funcio- } \\
\text { namento }\end{array}$ & $\begin{array}{l}\text { Profundidade média } \\
\text { do nível d'água (NA) }\end{array}$ & $\begin{array}{c}\text { Fonte primária } \\
\text { (bomba, linha e/ou } \\
\text { tanque) }\end{array}$ & $\begin{array}{c}\text { Presença de fase } \\
\text { livre }\end{array}$ & \\
\hline \multirow[t]{6}{*}{$\begin{array}{l}\text { Agência ambiental } \\
\text { responsável }\end{array}$} & $\begin{array}{l}\text { Gradiente hidráulico } \\
\text { máximo (i) }\end{array}$ & $\begin{array}{l}\text { Profundidade das } \\
\text { fontes primárias }\end{array}$ & $\begin{array}{c}\text { Máxima espessura } \\
\text { aparente de fase } \\
\text { livre }\end{array}$ & \\
\hline & Porosidade efetiva $\left(n_{e}\right)$ & $\begin{array}{l}\text { Combustíveis } \\
\text { vazados e volumes }\end{array}$ & & \\
\hline & $\begin{array}{l}\text { Fração de carbono } \\
\text { orgânico }\left(f_{o c}\right)\end{array}$ & & & \\
\hline & Condutividade hidráulica (K) & & & \\
\hline & $\begin{array}{c}\text { Concentração de aceptores } \\
\text { de elétrons }\end{array}$ & & & \\
\hline & $\mathrm{pH}$ & & & \\
\hline
\end{tabular}

\subsection{Análise de dados}

Após a coleta de dados, inicialmente foi criada uma matriz de correlação entre os parâmetros avaliados. Para os parâmetros que demonstraram maior correlação a análise foi aprofundada para avaliação da interação entre eles. Para apresentação dos dados, são usados gráficos tipo box-plot, indicando valores mínimos, máximos, quartis 25,50 e 75 , além da média. 0 percentil 90 também é usado para discussão dos resultados por incorporar a maioria dos dados avaliados (90\%) e permitir comparação com estudos realizados em outros locais (CONNOR et al., 2015). Valores discrepantes, com uma distância maior que 1,5 vezes o intervalo interquartil, foram considerados como extremos (outliers) e representados como pontos individualizados.

Além dos dados coletados diretamente nos relatórios de investigação, para a caracterização geológica regional utilizou-se o Mapa Geológico do Estado de São Paulo 1:750.000 (CPRM, 2006) e para a litologia regional utilizou-se o Mapa Pedológico do Estado de São Paulo 1:500.000 (OLIVEIRA et al., 1999). As áreas foram plotadas nesses mapas a partir das coordenadas geográficas obtidas durante o levantamento dos dados e então classificadas pelo tipo de solo e geologia. A geologia foi inicialmente classificada pelas unidades litoestratigráficas definidas por CPRM (2006) e, posteriormente, em quatro grupos: Complexo Cristalino; Bacia do Paraná; Bacias Terciárias e Quaternário.

Para avaliação da ocorrência de processos de degradação microbiológica foram avaliados parâmetros associados a esse processo, como: potencial de oxirredução; concentrações dos aceptores de elétrons (oxigênio, nitrato e sulfato); e presença e concentração de metano, considerado importante subproduto da degradação. Foram calculadas as solubilidades efetivas teóricas (Se) para os hidrocarbonetos com intuito de avaliar a ocorrência de cosolvência das substâncias ocasionada pelo etanol. A determinação da solubilidade efetiva foi feita pelo produto da fração molar típica do composto na gasolina no Brasil $\left(x_{i}\right)$ e da 
solubilidade do composto disponível na literatura $\left(\mathrm{S}_{\mathrm{i}}\right.$ ) (Equação 1) (NATIONAL CENTER FOR BIOTECHNOLOGY INFORMATION, 2020; CORSEUIL et al., 2004; SCHWARZENBACH et al., 2003).

$S_{e}=x_{i} S_{i}$

\section{Resultados e Discussão}

\subsection{Características gerais}

Foram analisados os processos de 516 áreas com contaminação por combustíveis. Deste total, 472 (91,5\%) continham relatório da etapa de investigação detalhada (CETESB, 2009). Na Tabela 2 apresenta-se o número absoluto de áreas onde foi possível obter a informação indicada e o percentual relacionado, além das medianas, máximos e mínimos para parâmetros numéricos. Os valores são reportados conforme encontrado nos relatórios, mesmo que fora da faixa natural, como concentração de OD de $18 \mathrm{mg} \mathrm{L}^{-1}$, que indica provavelmente erro de medição ou registro, ou influência de algum sistema de remediação, como a injeção oxigênio (biosparging) ou a utilização de ORC (oxygen releasing compounds) (JOHNSON; JOHNSON, 2012; BIANCHI-MOSQUERA et al.; 1994).

Apesar de na maioria das áreas já ter sido realizada a investigação detalhada, algumas informações básicas para construção do modelo conceitual de contaminação não foram localizadas em um número significativo das áreas. Por exemplo, informações sobre o meio físico foram apresentadas com maior frequência, enquanto as características geoquímicas da água foram relatadas numa minoria das áreas e, em geral, limitadas a concentração de oxigênio e pH. Características das fontes, como duração do vazamento e volume derramado também não foram encontradas na grande maioria dos casos (< $2 \%)$.

As plumas de benzeno foram delimitadas na direção longitudinal (no sentido do fluxo de água subterrânea) e transversalmente em mais de $70 \%$ das áreas (73,2\% e 72,4\%, respectivamente). Verticalmente, a delimitação foi realizada somente em 89 áreas (17,3\%). As extensões longitudinais e transversais das plumas de benzeno apresentaram quartil 75 inferior a $50 \mathrm{~m}$ (Figura 1a). Observa-se uma relação entre as medianas das extensões longitudinal, transversal e vertical das plumas de benzeno de (30:25:3). Em geral, dimensões similares nas direções longitudinal e transversal não são esperadas pelos processos de dispersão, sendo provavelmente uma consequência da presença de mais de uma fonte, heterogeneidades que causam a convergência de linhas de fluxo em camadas de maior permeabilidade ou alterações no sentido de fluxo devido a bombeamentos ou processos naturais, causando condições de fluxo transiente (ROLLE et al., 2009; GELHAR et al., 1992).

0 percentil 70 da extensão longitudinal das plumas de benzeno foi de $46,5 \mathrm{~m}$, e o percentil 90 foi de $73 \mathrm{~m}$, valor aproximadamente 40\% menor do observado por Connor et al. (2015) em 165 plumas nos EUA. Diversos processos podem interferir na extensão de plumas de contaminação e justificar essa diferença de resultado. Alguns fatores importantes que influenciam o tamanho da pluma incluem a velocidade de fluxo da água subterrânea, processos de adsorção e atenuação natural (destacando-se a biodegradação), além de características do vazamento como duração e volume de combustível vazado. Apesar da grande complexidade desses processos, a condutividade hidráulica (um dos parâmetros que controla a velocidade de fluxo) foi identificada como um dos principais parâmetros condicionante da extensão longitudinal das plumas (Figura 1b), principalmente para valores inferiores a $10^{-5} \mathrm{~cm} \mathrm{~s}^{-1}$, que estão quase sempre associados a plumas inferiores a $50 \mathrm{~m}$ (com uma única exceção). Nessas áreas a mediana das plumas é inferior com um nível de confiança de 95\% (valor-p menor que 0,04). Em grande parte das áreas (136), a condutividade hidráulica variou de $10^{-5}$ a $10^{-4} \mathrm{~cm} \mathrm{~s}^{-1}$, valor relativamente baixo normalmente associado a meios siltosos (FREEZE \& CHERRY, 1979), com mediana do comprimento longitudinal de aproximadamente $30 \mathrm{~m}$. Em contraste, não foi observada relação entre a condutividade hidráulica e as concentrações máximas de benzeno (coeficiente de correlação R2 de $\sim 9 \times 10-8$ ).

Também se observa que, em geral, as plumas com maiores extensões estão relacionadas a vazamentos mais recentes, de até 10 anos (Figura 2). A envoltória dos dados de comprimento da pluma em função da idade do vazamento indica que após 10 anos há um decréscimo significativo do comprimento da pluma. Essa tendência está provavelmente relacionada à exaustão da fonte e processos de atenuação natural, causando uma redução significativa das extensões da pluma ao longo dos anos. Assim, tanto os valores reduzidos de condutividade hidráulica quanto altas taxas de biodegradação podem justificar menores extensões de plumas de benzeno no Estado de São Paulo. Ressalta-se que os dados das extensões das plumas usados no estudo foram das maiores extensões reportadas nos relatórios disponíveis, em geral coletados nos relatórios de investigação detalhada, portanto antes da etapa de remediação. Assim, os comprimentos não devem ter sido afetados por processos de remediação. 
Tabela 2 - Principais medidas obtidas para os diferentes parâmetros

\begin{tabular}{|c|c|c|c|c|}
\hline Parâmetro & $\begin{array}{c}\text { Número total de } \\
\text { dados } \\
\text { disponíveis }\end{array}$ & Mediana & Máximo & Mínimo \\
\hline \multicolumn{5}{|l|}{ Caracterização física do meio } \\
\hline Descrição da granulometria & $428(82,95 \%)$ & - & - & - \\
\hline Descrição da pedologia & $31(6,01 \%)$ & - & - & - \\
\hline Identificação / Descrição do aquífero & $135(26,16 \%)$ & - & - & - \\
\hline $\mathrm{NA}(\mathrm{m})$ & $495(95,93 \%)$ & 3,3 & 23,4 & 0,425 \\
\hline $\mathrm{K}\left(\mathrm{cm} \mathrm{s}^{-1}\right)$ & $359(69,57 \%)$ & $7,3 \times 10^{-5}$ & $6,6 \times 10^{-2}$ & $7,9 \times 10^{-9}$ \\
\hline$n_{e}(-)$ & $319(61,82 \%)$ & $10 \%$ & $69 \%$ & $0,05 \%$ \\
\hline Foc (-) & $98(19,00 \%)$ & $0,59 \%$ & $11,0 \%$ & $0,010 \%$ \\
\hline \multicolumn{5}{|c|}{ Caracterização físico-química da água subterrânea } \\
\hline $\mathrm{OD}\left(\mathrm{mg} \mathrm{L}^{-1}\right)$ & $124(24,03 \%)$ & 1,5 & 18 & 0,0 \\
\hline $\mathrm{NO}_{3}\left(\mathrm{mg} \mathrm{L}^{-1}\right)$ & $5(0,97 \%)$ & 1,95 & 23 & 0,063 \\
\hline $\mathrm{SO}_{4}\left(\mathrm{mg} \mathrm{L}^{-1}\right)$ & $4(0,78 \%)$ & 8,35 & 24,6 & 0,0 \\
\hline $\mathrm{CH}_{4}\left(\mathrm{mg} \mathrm{L}^{-1}\right)$ & $16(3,10 \%)$ & 246 & 87200 & 0,416 \\
\hline $\mathrm{pH}$ & $199(38,57 \%)$ & 6,18 & 9,5 & 0,1 \\
\hline ORP $(\mathrm{mV})$ & $71(13,76 \%)$ & $-75,2$ & 500 & -380 \\
\hline \multicolumn{5}{|l|}{ Contaminantes em água subterrânea } \\
\hline $\mathrm{C}_{\mathrm{EtOH}}\left(\mu \mathrm{g} \mathrm{L}^{-1}\right)$ & $114(22,14 \%)$ & 5919 & $7,7 \times 10^{7}$ & 3 \\
\hline CBenzeno $_{\left(\mu g \mathrm{~L}^{-1}\right)}$ & $484(93,98 \%)$ & 752 & 377307 & 0 \\
\hline Colueno ( $\mu \mathrm{g} \mathrm{L}-1)$ & $478(92,82 \%)$ & 651 & 787797 & 0 \\
\hline CEtilbenzeno ( $\left.\mu g \mathrm{~L}^{-1}\right)$ & $480(93,20 \%)$ & 570 & 661000 & 0 \\
\hline $\mathrm{CX}_{\mathrm{X} i \operatorname{lenos}}\left(\mu \mathrm{g} \mathrm{L}^{-1}\right)$ & $480(93,20 \%)$ & 1994 & $2,8 \times 10^{6}$ & 0 \\
\hline $\mathrm{C}_{\text {Naftaleno }}\left(\mu \mathrm{g} \mathrm{L}^{-1}\right)$ & $479(93,00 \%)$ & 174 & 515626 & 0 \\
\hline$C_{\text {Antraceno }}\left(\mu g \mathrm{~L}^{-1}\right)$ & $403(78,25 \%)$ & 0,42 & 75342 & 0 \\
\hline LEtOH longitudinal (m) & $19(3,69 \%)$ & 29,1 & 147 & 12,5 \\
\hline LEtOH transversal (m) & $20(3,88 \%)$ & 17,0 & 78,9 & 8,8 \\
\hline Lbenzeno longitudinal (m) & $370(71,84 \%)$ & 29,1 & 227 & 1,5 \\
\hline Lbenzeno transversal $(\mathrm{m})$ & $370(71,84 \%)$ & 23,2 & 9375 & 0,7 \\
\hline Lbenzeno vertical $(\mathrm{m})$ & $92(17,83 \%)$ & 4,0 & 23 & 0,7 \\
\hline
\end{tabular}

Obs.: valores não detectados foram considerados iguais a zero para cálculo das estatísticas. 
Figura 1 - Dimensões das plumas de benzeno, a) em relação à direção, e b) dimensão longitudinal em relação a condutividade hidráulica $\left(\mathrm{cm} \mathrm{s}^{-1}\right)$
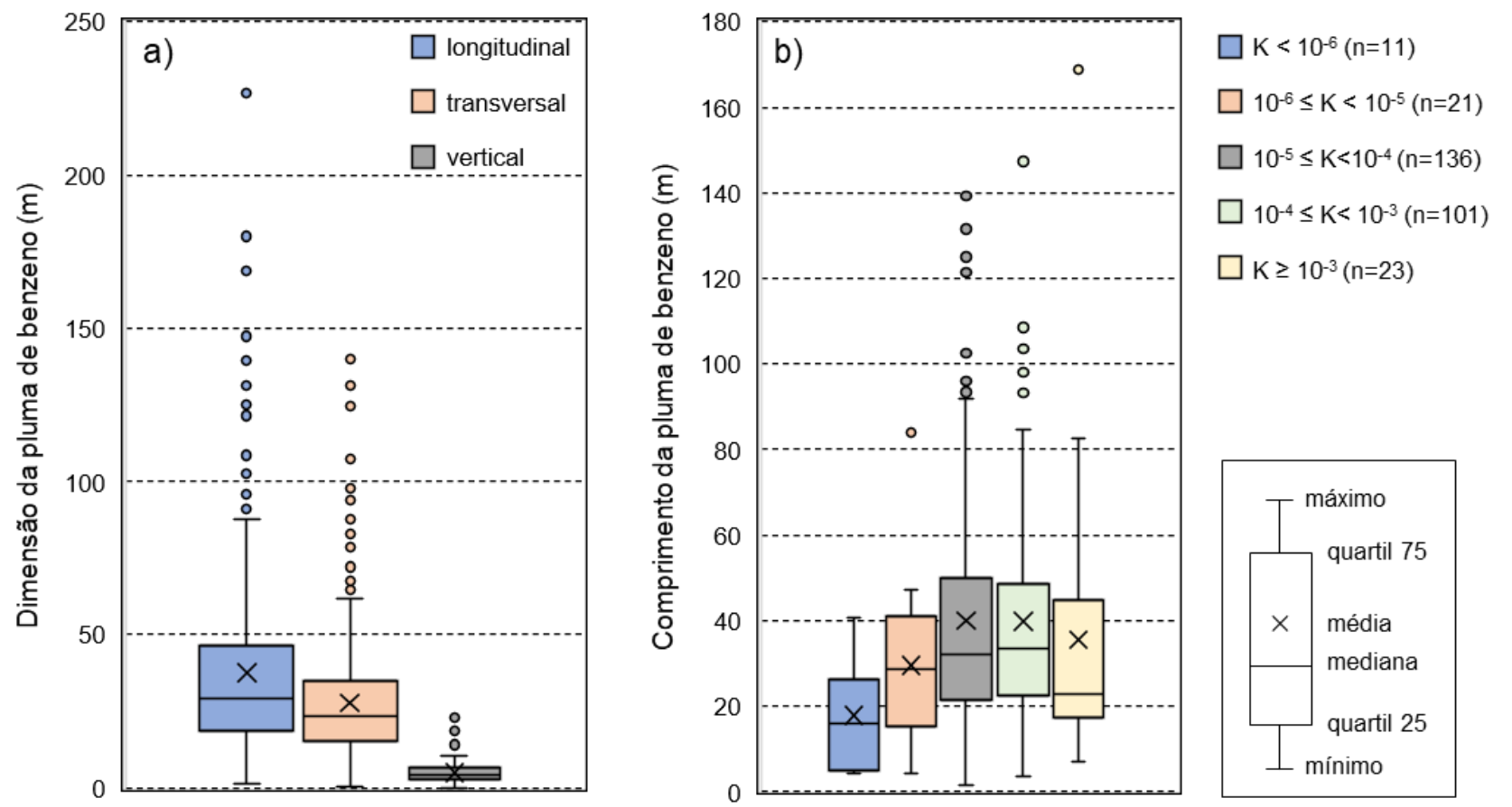

Figura 2 - Plumas de benzeno e idade estimada do vazamento

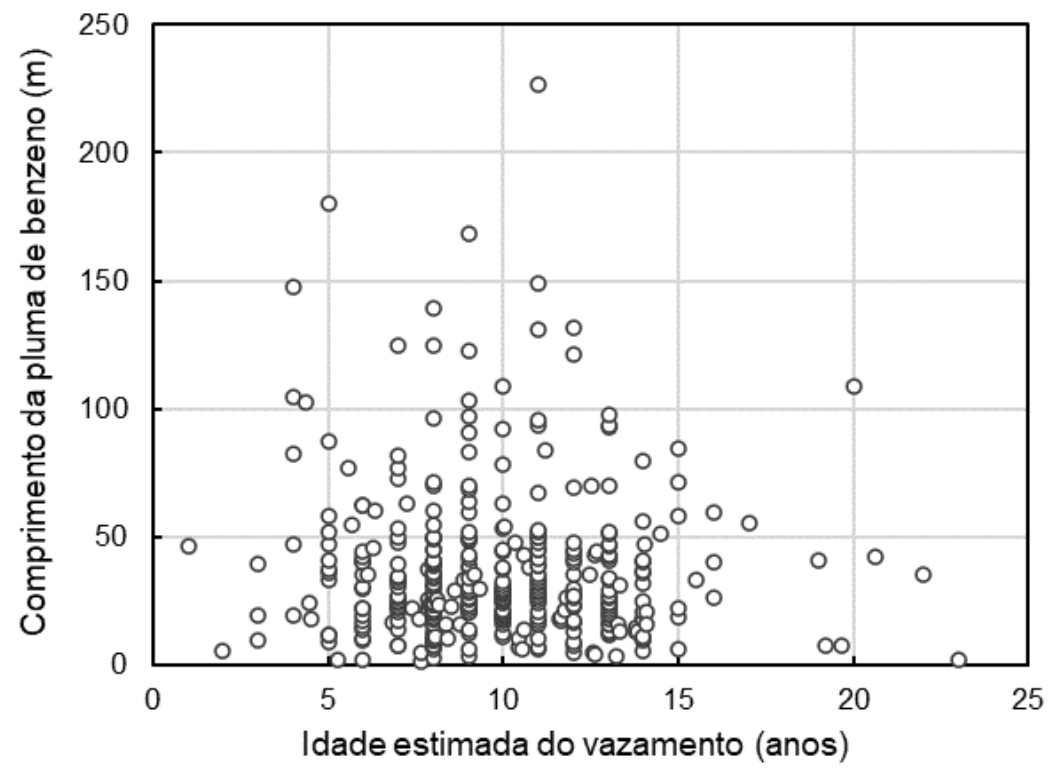

\subsection{Localização e comportamento da contaminação}

A maioria dos casos avaliados estão na Região Metropolitana de São Paulo, como pode ser observado na Figura 3. A maior parte das áreas avaliadas encontra-se em bacias terciárias (172 áreas), principalmente na Formação Resende, e no quaternário (131 áreas). As demais áreas se distribuem entre a ba- cia do Paraná (96 áreas) e Complexo Cristalino (87 áreas). A geologia regional não apresentou relação estatisticamente significativa com a condutividade hidráulica medida nas áreas ou com a extensão das plumas de benzeno (valores-p superiores a $0,05)$. Uma das razões para isso é que dentro da mesma formação existem variações locais significativas nas propriedades físicas. 
Figura 3 - Localização das áreas avaliadas

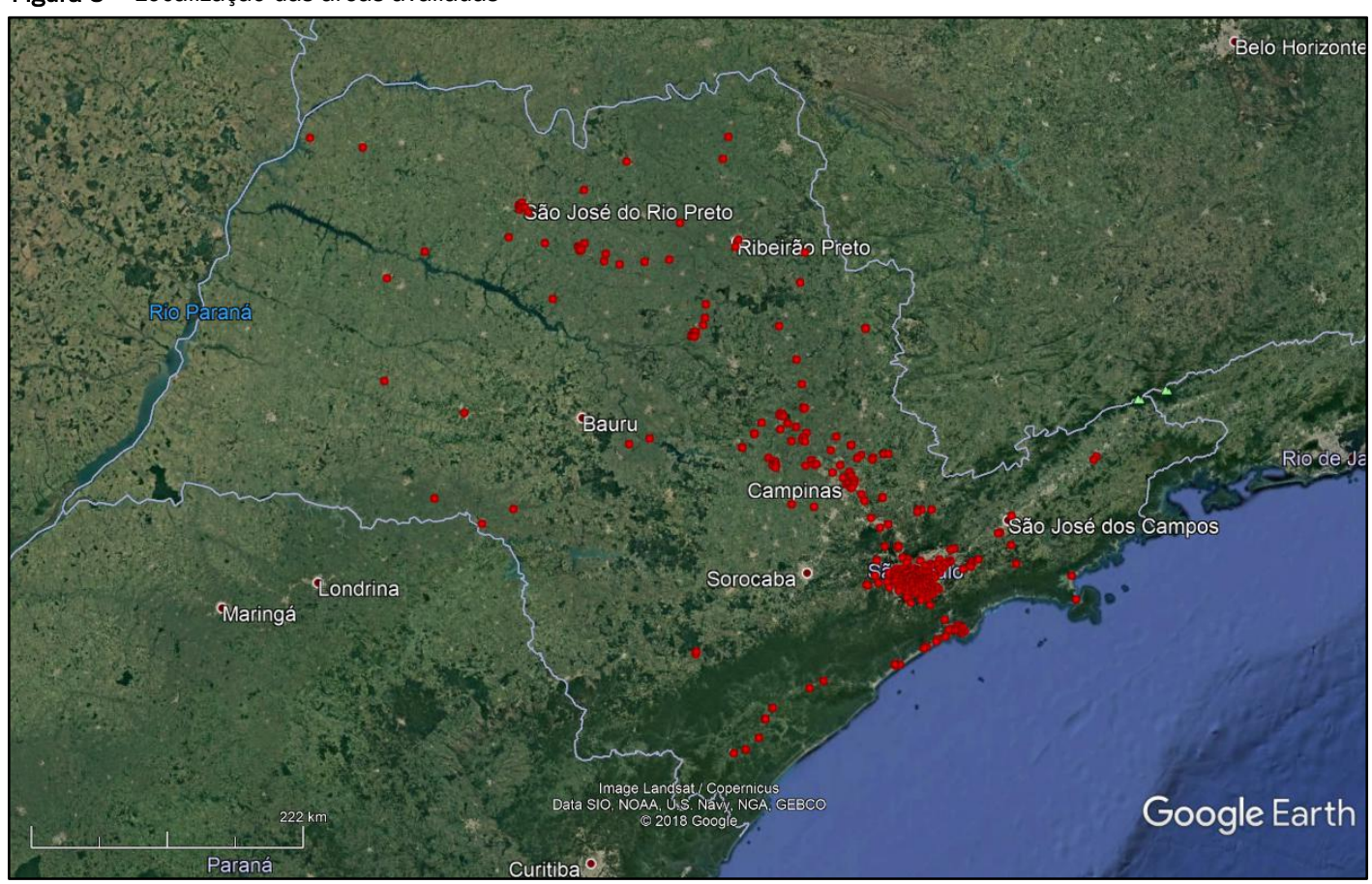

Fonte: adaptado de Google Earth (2019)

Além disso, com exceção das áreas onde há um fluxo vertical descendente significativo da água subterrânea, as plumas de contaminação por combustíveis líquidos se acumulam na parte superior do aquífero, próximo ao nível d'água (com mediana da profundidade de $3,3 \mathrm{~m}$ ). Nessas profundidades rasas a geologia regional tende a ser menos determinante das propriedades do meio, além do meio possivelmente ter sido alterado por ações antrópicas, como a construção de aterros. De acordo com o levantamento da pedologia, verificou-se que a maioria das áreas avaliadas se encontram na Região Metropolitana de São Paulo e outros centros urbanos no interior e no litoral do estado, totalizando 68,74\% das áreas em área urbana. Em áreas urbanas atualmente não há classificação pedogênica devido às mudanças causadas no solo nestas regiões por obras de engenharia e outras interferências antrópicas, sendo difícil identificar as tipologias predominantes devido a alteração da estrutura pedológica. Assim, ressalta-se a importância dos esforços para o estudo e classificação de solos urbanos (HUOT et al., 2015; MOREL et al., 2015). Nas áreas avaliadas fora de áreas urbanas, constatou-se a predominância de Latossolo e Argissolo, com $12,62 \%$ e $12,23 \%$ respectivamente. Esses dois tipos de solos são os mais comuns no Brasil e no estado de São Paulo, possuindo estágio avançado de desenvolvimento com horizonte B espesso para ambos os casos.

\subsection{Processos atuantes e impacto do etanol}

\subsubsection{Condições hidrogeoquímicas}

A média e a mediana das concentrações de oxigênio dissolvido (OD) na região das plumas foram inferiores a $2 \mathrm{mg} \mathrm{L}^{-1}$ (Figura 4).
Ressalta-se que o valor extremo de OD de $18 \mathrm{mg} \mathrm{L}^{-1}$ não foi incluído nessa análise. Os baixos valores encontrados indicam que o oxigênio provavelmente foi consumido pela atividade microbiológica, predominando condições anaeróbias no meio subsuperficial. Esse comportamento é esperado, já que na presença de hidrocarbonetos a biodegradação aeróbia acontece preferencialmente, resultando no consumo de oxigênio. Por exemplo, para a degradação de $1 \mathrm{~mol}$ de benzeno são consumidos 7,5 mols de $\mathrm{O}_{2}$. As concentrações de oxigênio dissolvido não apresentaram relação direta com as concentrações de hidrocarbonetos detectadas em água (Figura 5). Nas áreas com maior concentração de hidrocarbonetos (>10.000 $\mu \mathrm{g} \mathrm{L-1})$, a mediana e o percentil 75 da concentração de OD foram ligeiramente mais elevadas, de 1,9 e 2,9, respectivamente. Algumas hipóteses para esses valores superiores podem ser a biodegradação ainda estar no início ou não ter atuado de forma significativa, devido a outros fatores limitantes como: baixa concentração de nutrientes, vazamento recente (microrganismos em fase lag), contaminação em concentrações tóxicas aos microrganismos ou microbiota não adaptada aos contaminantes. Em áreas com menores concentrações de hidrocarbonetos $(<100$ $\mu \mathrm{g} \mathrm{L}^{-1}$ ) também foram encontrados valores relativamente maiores de OD (mediana de 1,6), possivelmente indicando a recuperação do aquífero em algumas áreas ou uma contaminação de menor magnitude que não tenha resultado num consumo significativo de OD.

Apesar das baixas concentrações de oxigênio dissolvido, o potencial de oxirredução (ORP) não indicou predominância de condições redutoras, sendo a mediana próxima de zero. Em geral, 
os valores de $\mathrm{pH}$ também não apresentaram alterações significativas do esperado para condições não impactadas, com mediana em torno de 6 . A degradação dos contaminantes orgânicos em condições anaeróbias pode levar a formação de metano $\left(\mathrm{CH}_{4}\right)$ na água subterrânea, que atingiu valores superiores a $1000 \mathrm{mg} \mathrm{L}^{-1}$ em duas das 16 áreas onde foi avaliada a desse composto. De acordo com estimativa apresentada em Gooddy \& Darling (2005), é necessária uma concentração mínima de $1,6 \mathrm{mg} \mathrm{L}^{-1}$ de $\mathrm{CH}_{4}$ na água subterrânea para que sejam atingidas concentrações iguais ou superiores ao limite inferior de ex- plosividade de 5\% no vapor. Em todas as áreas com resultados de $\mathrm{CH}_{4}$, somente uma apresentou concentração máxima inferior a 1,6 mg L-1, portanto, é esperado que nas demais áreas exista o potencial para liberação de gás e para que sejam atingidas concentrações iguais ou superiores ao limite inferior de explosividade de 5\% no vapor. Assim, considerando o predomínio de condições anaeróbias e ocorrência de metano, ressaltase a necessidade de monitoramento das concentrações de metano e explosividade com maior frequência para áreas contaminadas por hidrocarbonetos.

Figura 4 - Valores de OD ( $n=111), p H(n=199), \mathrm{CH}_{4}(\mathrm{n}=16)$ e ORP ( $\left.\mathrm{n=38}\right)$. Outlier e média de metano não incluídos (82700 e $5700 \mathrm{mg} \mathrm{L-1.}$ respectivamente)
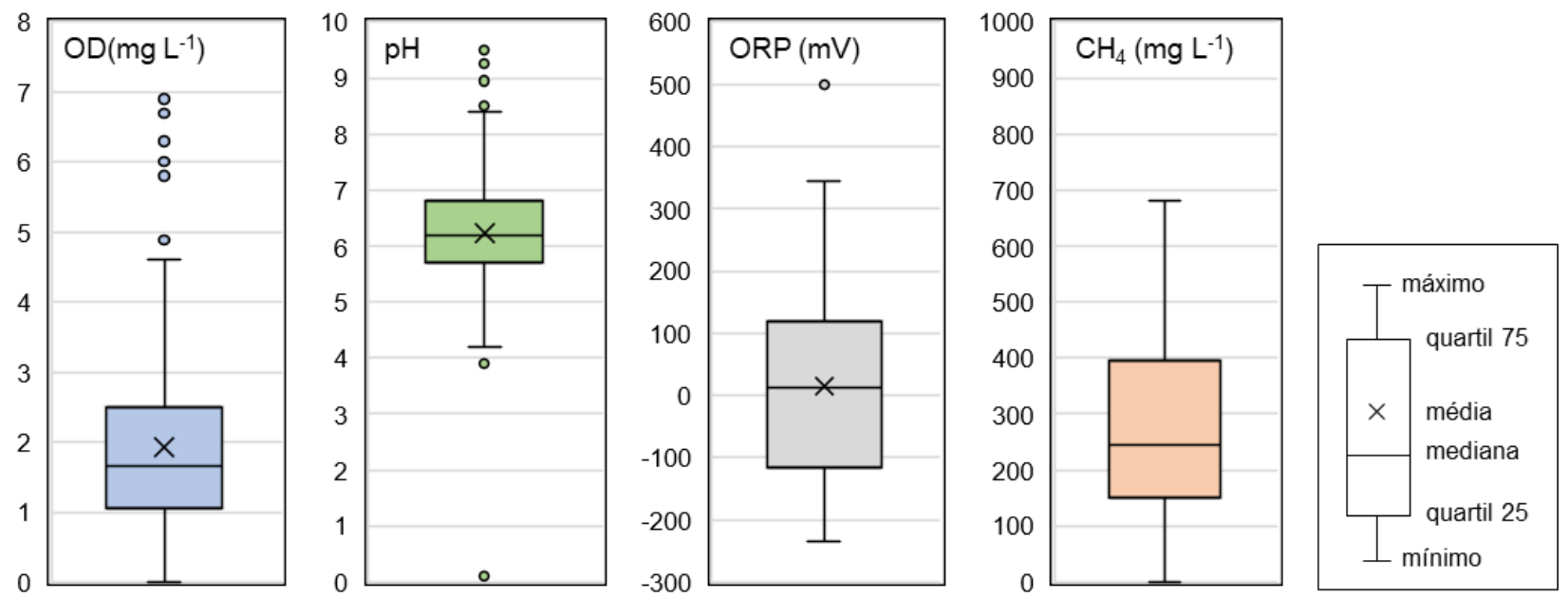

Figura 5 - Concentrações de OD x soma de BTEX $\left(\mu g \mathrm{~L}^{-1}\right)$
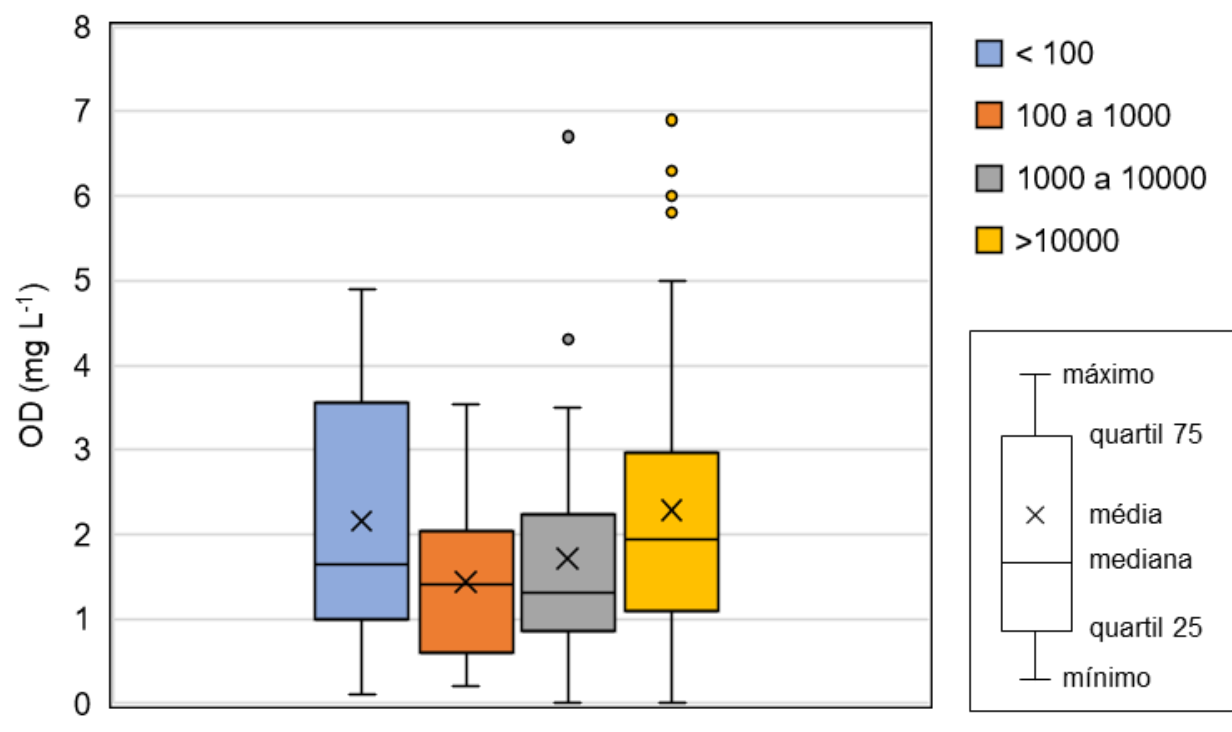

\subsubsection{Ocorrência e impactos do etanol}

Apenas em 214 áreas (41,5\%) as concentrações de etanol foram investigadas. Desse total, o etanol foi detectado somente em 57,5\% das áreas (123). A não-detecção de etanol, apesar de estar presente em pelo menos $20 \%$ da fração volumétrica da gasolina, pode ser causada por uma série de fatores. 0 etanol pode não ter atingido a água subterrânea em concentrações elevadas devido à retenção na zona não-saturada (BODELÃO et al., 2017; FREITAS e BARKER 2011; McDOWELL e POWERS 2003), pode ter sido transportado rapidamente (RECKHORN et al., 2001) e/ou sofrido rápida biodegradação (POWERS et al., 
2001, ALVAREZ e HUNT 2002, ZHANG et al., 2006). Além disso, podem ter sido empregadas técnicas de amostragem e/ou analíticas não adequadas para a detecção de etanol, uma vez que foram reportados limites de detecção de até $5000 \mu \mathrm{g} \mathrm{L-1}$ para o etanol. Para aqueles locais em que o etanol foi detectado acima do limite de detecção, a concentração máxima de etanol apresentou um valor médio de 40,2 mg L-1 e máximo de 379000 $\mathrm{mg} \mathrm{L-1}$.

Em 25 das 29 áreas com uma série histórica das concentrações de etanol (pelo menos três anos de monitoramento) foi observada uma redução maior ou igual a 99\% em suas concentrações em períodos de até 4 anos. 0 intervalo de tempo médio para atingir essa remoção nessas áreas foi de 2,4 anos. A persistência relativamente baixa provavelmente está associada à rápida biodegradação dessa substância, particularmente em temperaturas elevadas no Estado de São Paulo (temperaturas médias anuais próximas de $20^{\circ} \mathrm{C}$ ). Apesar do etanol ter baixa persistência, seus subprodutos de degradação, como ácidos graxos voláteis (ácidos acético, propiônico e butírico), não são monitorados em áreas contaminadas e podem persistir por períodos mais longos (WILSON et al., 2016; MA et al., 2011; FREITAS et al., 2010). Ressalta-se que apesar do rápido decaimento na maioria das áreas, as concentrações se mantiveram elevadas por períodos superiores a 5 anos em algumas delas. As áreas com maior persistência do etanol apresentaram concentrações iniciais bastante elevadas (na ordem de $10000 \mathrm{mg} \mathrm{L}^{-1}$ ). É provável que nessas áreas tenha acontecido o vazamento de etanol hidratado, que pode se acumular na zona não-saturada e franja capilar devido a sua baixa densidade por um longo período, atuando como uma fonte secundária para a pluma dissolvida (FREITAS e BARKER, 2013). As plumas de etanol também tiveram extensão relativamente pequena (mediana de $29 \mathrm{~m} \mathrm{e}$ percentil 90 de $60 \mathrm{~m}$ ), apesar do etanol ser completamente miscível em água e não apresentar retardamento significativo (ZHANG et al., 2006), indicativo da ocorrência de biodegradação.

A extensão das plumas de benzeno foi maior nas áreas onde foi detectada a presença de etanol, com mediana de 33,67 m, em comparação as áreas onde não foi detectada a presença de etanol (mediana de 26,43 m) (valor-p de 8.5×10-4). Essa mesma diferença de $7 \mathrm{~m}$ foi obtida em estudo de O'Reilly et al. (2016), baseado em uma avaliação de aproximadamente 200 áreas nos Estados Unidos. No entanto, no estudo de O'Reilly et al. (2016) não foi observada uma diferença significativa para altas e baixas de etanol, como seria esperado caso o etanol estivesse impactando a atenuação natural do benzeno. Não obstante, os autores avaliaram que a análise tinha grandes incertezas devido ao pequeno número de áreas com altas concentrações, superiores a $2000 \mathrm{mg} \mathrm{L}^{-1}$ (somente 7 ou 0,8\%) (O'REILLY et al., 2016). Na avaliação feita das contaminações no Estado de SP, foi observado um número mais significativo de áreas com concentrações elevadas, $17 \%$ do total das áreas onde foi feita análise de etanol tinham concentrações superiores a $2000 \mathrm{mg} \mathrm{L}^{-1}$, possivelmente associadas a vazamentos de etanol hidratado.
Nas áreas onde foi detectada a presença de etanol em concentrações mais elevadas (> $1000 \mathrm{mg} \mathrm{L}^{-1}$ ), as plumas de benzeno apresentaram maiores extensões, com diferença mais significativa no quartil superior e valores máximos (Figura 6). Esse resultado é indicativo do impacto de etanol na taxa de atenuação natural dos hidrocarbonetos, sendo que concentrações elevadas de etanol como as observadas podem ter impactos diretos sobre os microrganismos responsáveis pela biodegradação. De acordo com Powers et al. (2001), concentrações de etanol entre $10^{4}$ a $10^{5} \mathrm{mg} \mathrm{L}^{-1}$ causam inibição da atividade microbiana, e concentrações superiores a $10^{5} \mathrm{mg} \mathrm{L}^{-1}$ causam inativação da maior parte dos microrganismos. Wilson et al. (2016) indicaram que concentrações superiores a $42 \mathrm{mg} \mathrm{L-1}$ inibiram a degradação de tolueno em condições anaeróbias.

Assim como a extensão das plumas de benzeno foi maior nas áreas com maiores concentrações de etanol, em geral, maiores concentrações de hidrocarbonetos foram encontradas nas áreas onde também foi identificada a presença de etanol na água subterrânea (Figura 7). Os maiores aumentos de concentração de hidrocarbonetos aparecem associados às maiores concentrações de etanol (Figura 8), e de forma mais significativa para os compostos mais hidrofóbicos, como os xilenos. Esse resultado pode estar associado à ocorrência de cosolvência. Nesse processo, altas concentrações de etanol favorecem a transferência de hidrocarbonetos para a fase aquosa, aumentado a solubilidade desses compostos (solubilidade efetiva). 0 efeito de cosolvência é mais significativo para compostos mais hidrofóbicos, ou seja, com maior valor do coeficiente de partição octanol-água (Kow) (RAMA et al.; 2019; CORSEUIL et al. 2004).

Na Tabela 3 são apresentados os valores calculados da solubilidade efetiva de alguns hidrocarbonetos. Ressalta-se que para os xilenos, além do o-xileno, outros dois isômeros estão presentes na gasolina, $\mathrm{m}$ e $\mathrm{p}$-xileno. Esses compostos apresentam propriedades similares ao o-xileno e estão presentes na gasolina em concentração em torno de três vezes superior ao o-xileno (SILVA et al., 2009). Comparando-se os valores da tabela (multiplicando o valor do o-xileno por quatro para considerar os demais isômeros) com os resultados apresentados na Figura 8, observa-se que, para as concentrações mais elevadas de etanol, as medianas das concentrações de etilbenzeno e xilenos são similares à concentração máxima esperada (solubilidade efetiva). Isso indica que em metade desses casos são observadas concentrações superiores à solubilidade efetiva, sendo os valores máximos aproximadamente 2,5 vezes superior a solubilidade efetiva para os dois compostos. Para o naftaleno, a mediana foi aproximadamente 10 vezes maior que a solubilidade efetiva. Alguns processos podem resultar em concentrações na água maiores que a solubilidade efetiva, como mudança na composição do combustível ao longo do tempo, devido à biodegradação e a dissolução dos compostos mais solúveis mais rapidamente. No entanto, considerando a associação de concentrações elevadas de etanol e dos hidrocarbonetos mais hidrofóbicos é possível que cosolvência esteja ocorrendo de forma significativa nessas localidades. 
Figura 6 - Comprimento da pluma de benzeno em função das concentrações de etanol

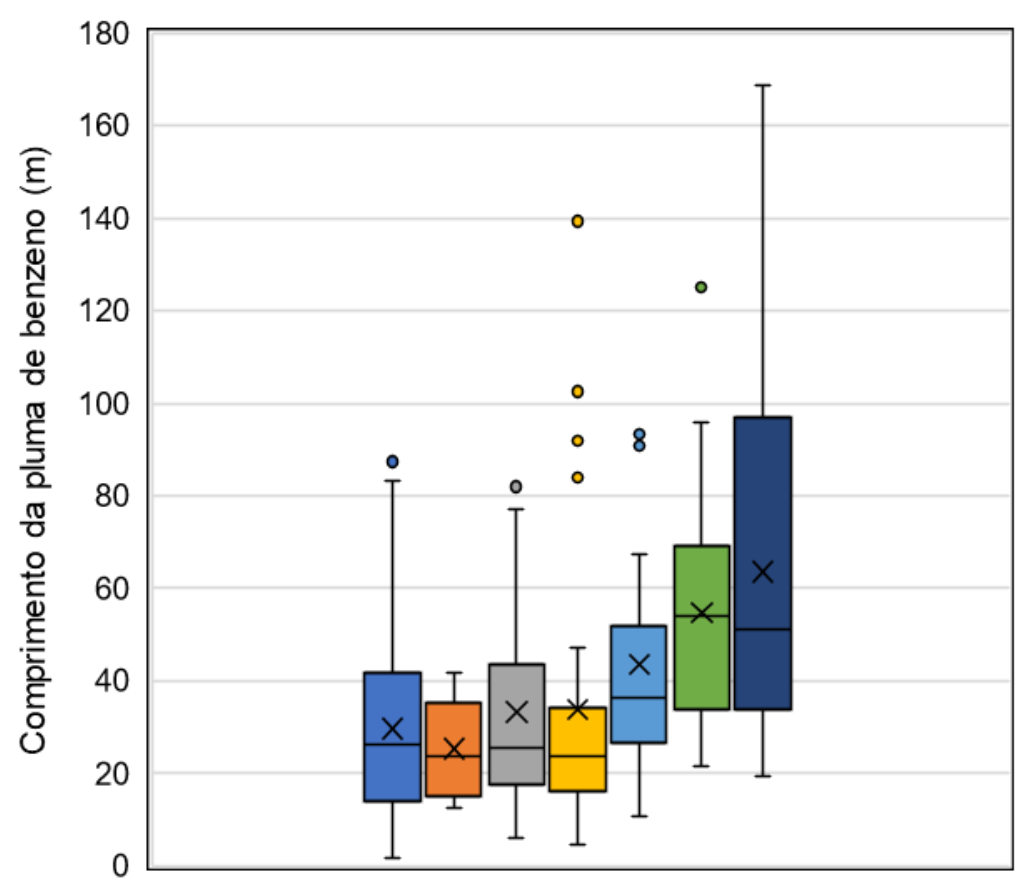

$\square \operatorname{ND}(\mathrm{n}=69)$

$\square 0$ a $1 \mathrm{mg} / \mathrm{L}(\mathrm{n}=9)$

$\square 1$ a $10 \mathrm{mg} / \mathrm{L}(\mathrm{n}=17)$

$\square 10$ a $100 \mathrm{mg} / \mathrm{L}(\mathrm{n}=29)$

$\square 100$ a $1000 \mathrm{mg} / \mathrm{L}(\mathrm{n}=16)$

$\square 1000$ a $10000 \mathrm{mg} / \mathrm{L}(\mathrm{n}=19)$

$\square>10000 \mathrm{mg} / \mathrm{L}(\mathrm{n}=15)$

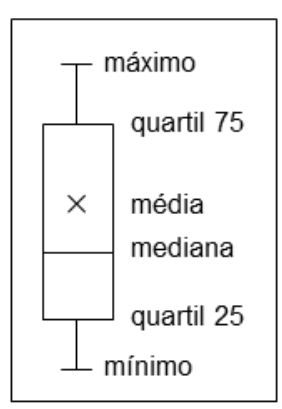

Figura 7 - Comparação das concentrações de hidrocarbonetos nas áreas com e sem detecção de etanol (B: benzeno, T: tolueno; E: etilbenzeno; X: xilenos; N: naftaleno)

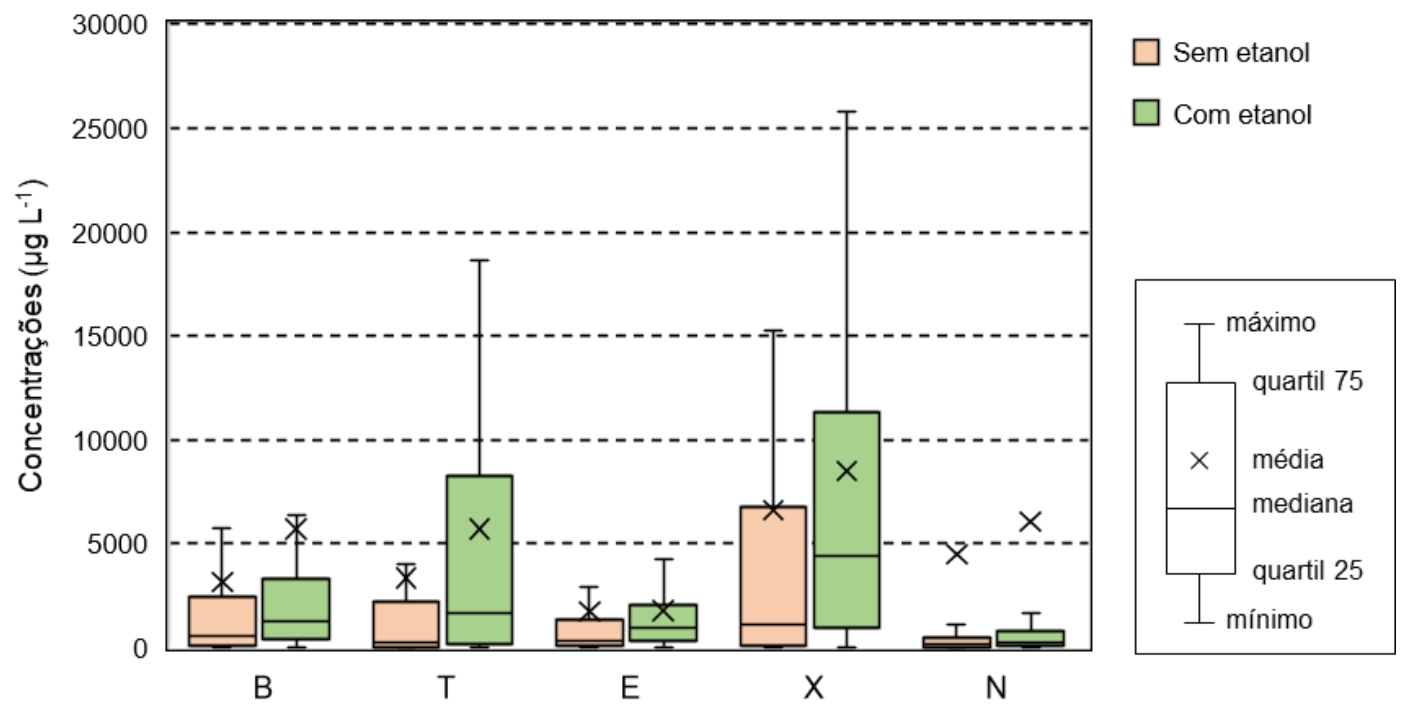


Figura 8 - Concentrações de hidrocarbonetos por faixa de concentração de etanol. (B: benzeno, T: tolueno; E: etilbenzeno; X: xilenos; $\mathrm{N}$ : naftaleno)

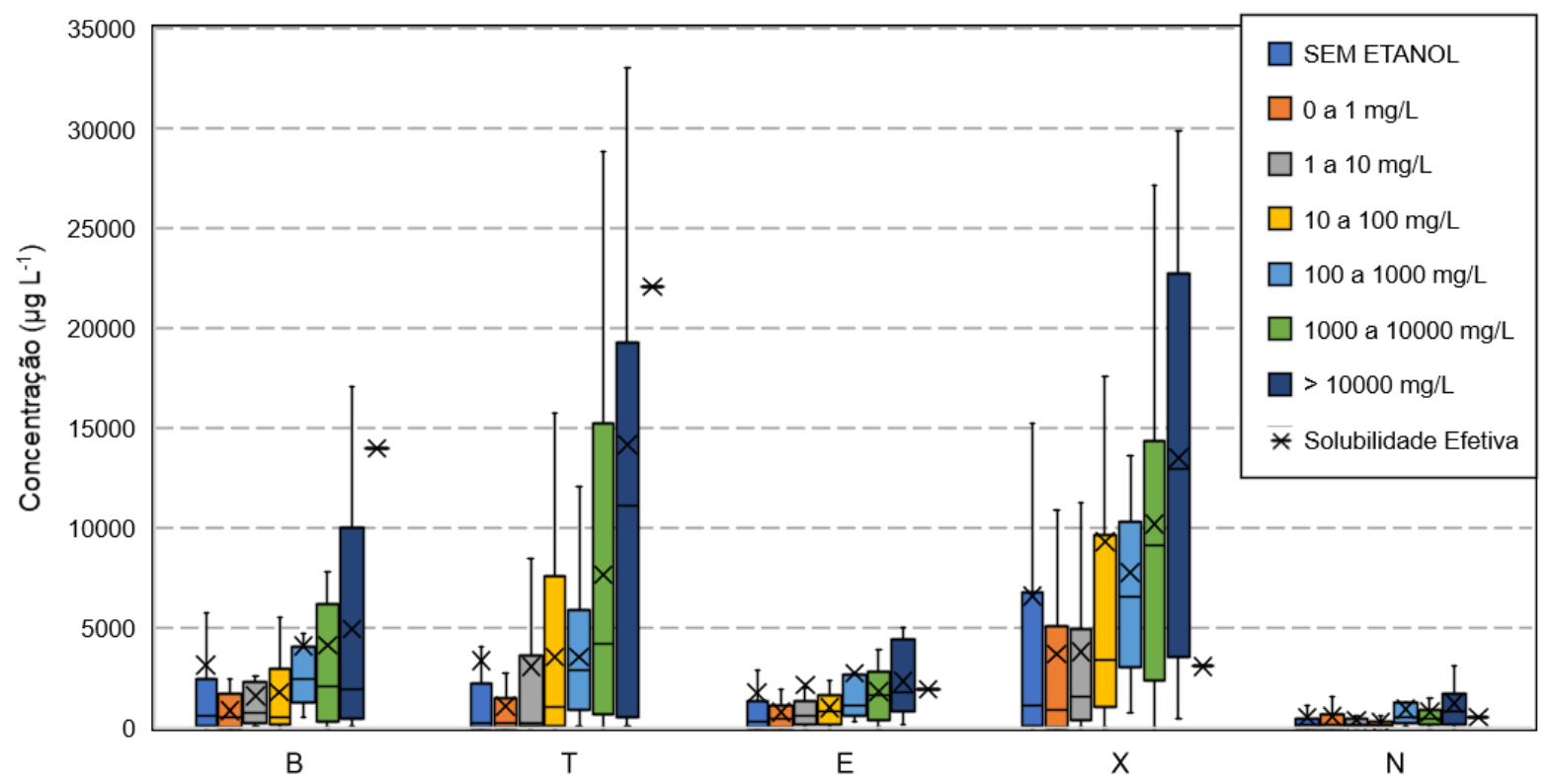

Tabela 3 - Propriedades dos compostos de interesse

\begin{tabular}{lcccc}
\hline Composto & log Kow & $\begin{array}{c}\text { Fração molar } \\
\text { na gasolina }\end{array}$ & $\begin{array}{c}\text { Solubilidade } \\
\left(\mathrm{mg} \mathrm{L}^{-1}\right)\end{array}$ & $\begin{array}{c}\text { Solubilidade Efetiva } \\
\left(\mu \mathrm{g} \mathrm{L}^{-1}\right)\end{array}$ \\
\hline benzeno & 2,13 & 0,0078 & 1790 & 14000 \\
tolueno & 2,73 & 0,0420 & 526 & 22090 \\
etilbenzeno & 3,15 & 0,0111 & 170 & 1900 \\
o-xileno & 3,12 & 0,0170 & 180 & 3060 \\
naftaleno & 3,30 & 0,0060 & $86 *$ & 516 \\
\hline
\end{tabular}

Fonte: Adaptado de Corseuil et al. (2004) e National Center for Biotechnology Information (2020).

*A solubilidade do naftaleno foi corrigida da fase sólida para líquida (SCHWARZENBACH et al., 2003)

\section{CONCLUSÕES}

Postos revendedores de combustíveis estão presente em grande quantidade, principalmente nas áreas urbanas, e são uma fonte potencial de contaminação por compostos aromáticos (principalmente benzeno, tolueno, etilbenzeno e xilenos) para os solos e as águas subterrâneas. Baseado num levantamento de 516 áreas contaminadas por postos de combustíveis no Estado de São Paulo, foi verificado que as plumas de benzeno na água subterrânea têm extensão relativamente pequena, com $90 \%$ das áreas apresentando plumas com extensão inferior a $73 \mathrm{~m}$. Esse comportamento está provavelmente associado a dois fatores. 0 primeiro é a localização das áreas em locais com condutividade hidráulica relativamente baixa (aproximadamente $60 \%$ das áreas com $\mathrm{K}<10^{-4} \mathrm{~cm} \mathrm{~s}^{-1}$ ), limitando a velocidade de transporte por advecção. 0 segundo fator é a ocorrência significativa de atenuação natural. A ocorrência de processos de biodegradação fica evidenciada pela predominância de condições anaeróbias (OD $<2 \mathrm{mg} \mathrm{L}^{-1}$ ) e detecção de subprodutos (como metano) em concentrações significativas na maioria das áreas onde foi analisado.
Plumas de benzeno com maiores extensões e maiores concentrações de hidrocarbonetos na água subterrânea foram associadas a concentrações de etanol superiores a $1000 \mathrm{mg} \mathrm{L}^{-1}$, possivelmente um efeito da combinação da diminuição de taxas de atenuação natural e cosolvência. Ainda assim, mesmo nas áreas com concentrações de etanol superiores a 10.000 mg L-1 em $75 \%$ das áreas a extensão das plumas de benzeno foi inferior a $100 \mathrm{~m}$.

\section{AGRADECIMENTOS}

Os autores agradecem o apoio financeiro recebido da Shell Global Solutions US. Também agradecemos a Companhia Ambiental do Estado de São Paulo (CETESB) pelo acesso aos processos.

\section{REFERÊNCIAS}

ALVAREZ, P.J.J., HUNT, C.S. The effect of fuel alcohol on monoaromatic hydrocarbon biodegradation and natural attenuation: review article. Revista Latinoamericana de Microbiología v. 44, p. 83-104, 2002. 
ANP (Agência Nacional do Petróleo, Gás Natural e Biocombustíveis - Brasil). Anuário Estatístico Brasileiro do Petróleo, Gás Natural e Biocombustíveis: 2019. Agência Nacional do Petróleo, Gás Natural e Biocombustíveis. Rio de Janeiro. 2019.

ARAÚJO-MOURA, A. A. C. DE; CAFFARO FILHO, R. A. Panorama do gerenciamento de áreas contaminadas no Brasil após a resolução CONAMA 420/09. Águas Subterrâneas, v. 29, n. 2, p. 202, 2015. https://doi.org/10.14295/ras.v29i2.27972

ATTEIA, O.; GUILLOT, C. Factors controlling BTEX and chlorinated solvents plume length under natural attenuation conditions. Journal of Contaminant Hydrology, v. 90, n. 1-2, p. 81-104, 2007. https://doi.org/10.1016/i.jconhyd.2006.09.012

BELINCANTA, J.; ALCHORNE, J. A.; SILVA, M.T. The Brazilian experience with ethanol fuel: Aspects of production, use, quality and distribution logistics. Brazilian Journal of Chemical Engineering, v. 33, n. 4, p. 1091-1102, 2016. https://doi.org/10.1590/0104-6632.20160334s20150088

BODELÃO, T. G. et al. Importância dos horizontes do solo na distribuição de gasolina com etanol na zona não saturada em solo tropical. Águas Subterrâneas, v. 31, n. 4, p. 413, 2017. https://doi.org/10.14295/ras.v31i4.28924

CETESB (Companhia Ambiental do Estado de São Paulo). Decisão de Diretoria n 263/2009/p, de 20 de outubro de 2009.

CETESB (Companhia Ambiental do Estado de São Paulo). Relatório de Áreas Contaminadas e Reabilitadas no Estado de São Paulo - Dezembro de 2019. Disponível em: https://cetesb.sp.gov.br/areas-contaminadas/relacao-de-areas-contaminadas/. 2020.

CONNOR, J. A.; KAMATH, R.; WALKER, K. L.; MCHUGH, T. E. Review of quantitative surveys of the length and stability of MTBE, TBA, and benzene plumes in groundwater at UST sites. Groundwater, v. 53, n. 2, p. 195-206, 2015. https://doi.org/10.1111/gwat.12233

CORSEUIL, H.X., HUNT, C.S., SANTOS, R.C.F., ALVAREZ, P.J.J.. The influence of the gasoline oxygenate ethanol on aerobic and anaerobic BTX biodegradation. Water Research, v. 32, p. 20652072, $1998 . \quad$ https://doi.org/10.1016/S00431354(97)00438-7

CORSEUIL, H.X., KAIPPER, B.I.A., FERNANDES, M. Cosolvency effect in subsurface systems contaminated with petroleum hydrocarbons and ethanol. Water Research, v. 38, n. 6, 1449-1456, 2004. https://doi.org/10.1016/i.watres.2003.12.015

CPRM (Companhia de Pesquisa de Recursos Minerais - Serviço Geológico do Brasil). Mapa Geológico do Estado de São Paulo: Breve descrição das unidades litoestratigráficas aflorantes no Estado de São Paulo. Escala 1:750000. 173 p, 2006.

DEEB, R.A., SHARP, J.O., STOCKING, A., MCDONALD, S., WEST, K.A., LAUGIER, M., ALVAREZ, P.J.J., KAVANAUGH, M.C., ALVAREZ-
COHEN, L. Impact of ethanol on benzene plume lengths: microbial and modeling studies. Journal of Environmental Engineering, $\quad n .128, \quad$ p. $868-875,2002$. https://doi.org/10.1061/(ASCE)0733-9372(2002)128:9(868)

FERREIRA, R. M.; LOFRANO, F. C.; MORITA, D. M. Remediação de áreas contaminadas: uma avaliação crítica da legislação brasileira. Engenharia Sanitaria e Ambiental, v. 25, n. 1, p. 115125, $2020 . \quad$ https://doi.org/10.1590/s141341522020168968

FIRTH, S.; HILDENBRAND, B.; MORGAN, P. Ethanol effects on the fate and transport of gasoline constituents in the UK. Science of the Total Environment, v. 485-486, n. 1, p. 705-710, 2014. https://doi.org/10.1016/j.scitotenv.2014.02.119

FREEZE, A.R., CHERRY, J. A.. Groundwater. Englewood Cliffs, NJ: Prentice-Hall, Inc, 1979.

FREITAS, J. G., FLETCHER, B., ARAVENA, R., BARKER, J. F. Methane production and isotopic fingerprinting in ethanol fuel contaminated sites. Ground Water, v. 48, n. 6, p. 844-857, 2010. https://doi.org/10.1111/i.1745-6584.2009.00665.x

FREITAS, J. G.; BARKER, J. F. Oxygenated gasoline release in the unsaturated zone - Part 1: Source zone behavior. Journal of Contaminant Hydrology, v. 126, n. 3-4, p. 153-166, 1 nov. 2011. https://doi.org/10.1016/i.jconhyd.2011.07.003

FREITAS, J. G.; BARKER, J. F. Denatured ethanol release into gasoline residuals, Part 1: source behaviour. Journal Of Contaminant Hydrology, v. 148, p. 67-78, 2013. https://doi.org/10.1016/i.jconhyd.2012.12.010

FREITAS, J. G.; MOCANU, M. T.; ZOBY, J. L. G.; MOLSON, J. W.; BARKER, J. F. Migration and fate of ethanol-enhanced gasoline in groundwater: a modelling analysis of a field experiment. Journal of Contaminant Hydrology, v. 119, n. 1-4, p. 25-43, 2011. https://doi.org/10.1016/i.jconhyd.2010.08.007

FREITAS, J. G., MOCANU, M. T., ZOBY, J. L. G., MOLSON, J. W., BARKER, J. F. Migration and fate of ethanol-enhanced gasoline in groundwater: a modelling analysis of a field experiment. Journal of Contaminant Hydrology, v. 119, n. 1-4, p. 25-43, 25 jan. 2011. https://doi.org/10.1016/j.jconhyd.2010.08.007

GELHAR, L. W., WELTY, C., \& REHFELDT, K. R. A critical review of data on field-scale dispersion in aquifers. Water Resources Research, v. 28, n. 7, p. 1955-1974, 1992. https://doi.org/10.1029/92WR00607

GOODDY, D.C., DARLING, W.G. The potential for methane emissions from groundwaters of the UK. Science of the Total Environment, v. 339, no. 1-3, p. 117-126, 2005. https://doi.org/10.1016/i.scitotenv.2004.07.019

HUOT, H., SIMONNOT, M.-O., MOREL, J. L. Pedogenetic Trends in Soils Formed in Technogenic Parent Materials. Soil Science, v. 180, n. 4/5, p. 182-192, 2015. https://doi.org/10.1097/SS.0000000000000135 
JOHNSON, R.L.; JOHNSON, P.C.; Chapter 8 - In Situ Sparging for Delivery of Gases in the Subsurface; in KITANIDIS, P.K., MCCARTY P.L. (eds) Delivery and Mixing in the Subsurface: Processes and Design Principles for In Situ Remediation, 325 p., Springer: Nova lorque, 2012. https://doi.org/10.1007/978-14614-2239-6 8

LOGESHWARAN, P. et al. Petroleum hydrocarbons $(\mathrm{PH})$ in groundwater aquifers: An overview of environmental fate, toxicity, microbial degradation and risk-based remediation approaches. Environmental Technology and Innovation, v. 10, p. 175-193, 2018. https://doi.org/10.1016/j.eti.2018.02.001

MA, J., XIU, Z., MONIER, A. L., MAMONKINA, I., ZHANG, Y., HE, Y., STAFFORD, B. P., RIXEY, W. G., ALVAREZ, P. J. J. Aesthetic Groundwater Quality Impacts from a Continuous Pilot-Scale Release of an Ethanol Blend. Ground Water Monitoring \& Remediation, v. 31, n. 3, p. 47-54, 2011. https://doi.org/10.1111/i.1745-6592.2011.01334.x

MA, J.; RIXEY, W. G.; ALVAREZ, P. J. J. Microbial processes influencing the transport, fate and groundwater impacts of fuel ethanol releases. Current Opinion in Biotechnology, v. 24, n. 3, p. 457-466, 2013. $\quad$ https://doi.org/10.1016/i.copbio.2012.09.005

MACKAY, D.M., DE SIEYES, N.R., EINARSON, M.D., FERIS, K.P., PAPPAS, A.A., WOOD, I.A., JACOBSON, L., JUSTICE, L.G., NOSKE, M.N., SCOW, K.M., WILSON, J.T. Impact of ethanol on the natural attenuation of benzene, toluene, and o-xylene in a normally sulfate-reducing aquifer. Environmental Science \& Technology, v. 40, n. 19, p. 6123-6130, 2006. https://doi.org/10.1021/es060505a

MAPA (Ministério da Agricultura, Pecuária e Abastecimento). Portaria MAPA $n^{\circ} 75$, de 5 de março de 2015. Diário Oficial da União. 6 mar 2015; Número 44, Seção 1, pg. 17, 2015.

MCDOWELL, C. J., POWERS, S. E. Mechanisms affecting the infiltration and distribution of ethanol-blended gasoline in the vadose zone. Environmental Science \& Technology, v. 37, n. 9, p. 1803-1810, 2003. https://doi.org/10.1021/es025976l

MICHELLON, E.; SANTOS, A. A. L.; RODRIGUES, J. R. A. Breve descrição do Proálcool e perspectivas futuras para o etanol produzido no Brasil. In: Congresso da Sociedade Brasileira de Economia, Administração e Sociologia Rural, 46., 2008, Rio Branco. Anais... Rio Branco: BNDES, 2008.

MOREL, J. L., CHENU, C., LORENZ, K. Ecosystem services provided by soils of urban, industrial, traffic, mining, and military areas (SUITMAs). Journal of Soils and Sediments, v. 15, n. 8, p. 1659-1666, 2015. https://doi.org/10.1007/s11368-0140926-0

NATIONAL CENTER FOR BIOTECHNOLOGY INFORMATION. PubChem Database. Disponível em: https://pubchem.ncbi.nlm.nih.gov/compound/Naphthalene. Acesso em 7 abril de 2020.
OLIVEIRA, J.B., CAMARGO, M.N., ROSSI, M. CALDERANO FILHO, B. Mapa pedológico do Estado de São Paulo: Legenda expandida. Campinas: Instituto Agronômico; Rio de Janeiro: Embrapa Solos. 1999. Disponível em: www.infoteca.cnptia.embrapa.br/infoteca/handle/doc/336272.

O'REILLY, K., ESPINO DEVINE, C., SIHOTA, N., NORTH, K. An Empirical Evaluation of the Influence of Ethanol on Natural Attenuation of Gasoline Constituents. Groundwater Monitoring and Remediation, v. 36, n. 3, p. 62-72, 2016. https://doi.org/10.1111/gwmr.12165

POWERS, S.E., HUNT, C.S., HEERMANN, S.E., CORSEUIL, H.X., RICE, D., ALVAREZ, P.J.J. The transport and fate of ethanol and BTEX in groundwater contaminated by gasohol. Critical Reviews in Environmental Science and Technology, v. 31, n. 1, p. 79123, 2001. https://doi.org/10.1080/20016491089181

RAMA, F.; RAMOS, D.T.; MULLER, J.B.; CORSEUIL, H.X. Flow field dynamics and high ethanol content in gasohol blends enhance BTEX migration and biodegradation in groundwater. Journal of Contaminant Hydrology, v. 222, n. 2018, p. 17-30, 2019. https://doi.org/10.1016/i.jconhyd.2019.01.003

RECKHORN, S. B. F.; ZUQUETTE, L. V.; GRATHWOHL, P. Experimental Investigations of Oxygenated Gasoline Dissolution. Journal of Environmental Engineering, v. 127, n. 3, p. 208-216, mar. 2001. https://doi.org/10.1061/(ASCE)07339372(2001)127:3(208)

ROLLE, M.; EBERHARDT, C.; CHIOGNA, G.; CIRPKA, O.A.; GRATHWOHL, $P$. Enhancement of dilution and transverse reactive mixing in porous media: Experiments and model-based interpretation. Journal of Contaminant Hydrology, v. 110, n. 3-4, p. 130142, 2009. https://doi.org/10.1016/i.jconhyd.2009.10.003

SCHWARZENBACH, R.P., GSCHWEND, P.M., IMBODEN, D.M. Environmental Organic Chemistry, $2^{\mathrm{a}}$ ed. Hoboken, NJ: John Wiley \& Sons, 2003. https://doi.org/10.1002/0471649643

SEAGREN, E. A.; BECKER, J. G. Review of natural attenuation of BTEX and MTBE in groundwater. Practice Periodical of Hazardous, Toxic, and Radioactive Waste Management, v. 6, n. 3, p. 156-172, 2002. https://doi.org/10.1061/(ASCE)1090025X(2002)6:3(156)

SILVA, F. L. D. N., DOS SANTOS, J. R., NETO, J. M. M., DA SILVA, R. L. G. D. N. P., FLUMIGNAN, D. L., DE OLIVEIRA, J. E. Determinação de benzeno, tolueno, etilbenzeno e xilenos em gasolina comercializada nos postos do estado do Piauí. Química Nova, v. 32, n. 1, p. 56-60, 2009. https://doi.org/10.1590/S010040422009000100011

STEINER, L. V.; RAMOS, D.T.; LIEDKE, A.M.R.; SERBENT, M.P.; CORSEUIL, H.X. Ethanol content in different gasohol blend spills influences the decision-making on remediation technologies. Journal of Environmental Management, v. 212, p. 8-16, 2018. https://doi.org/10.1016/i.jenvman.2018.01.071 
WILSON, J. T.. ADAIR, C.; WHITE, H.; HOWARD, R.L. Effect of Biofuels on Biodegradation of Benzene and Toluene at Gasoline Spill Sites. Groundwater Monitoring and Remediation, v. 36, n. 4, p. 50-61, 2016. https://doi.org/10.1111/gwmr.12187

WORLD HEALTH ORGANIZATION (WHO). Guidelines for drinkingwater quality, Health criteria and other supporting information, second ed., vol. 2. World Health Organization, Geneva, 1996.
ZHANG, Y., IMTIYAZ A.K., XUN-HONG C., SPALDING, R.F. Transport and Degradation of Ethanol in Groundwater. Journal of Contaminant Hydrology, v. 82, n. 3-4, p. 183-94, 2006. https://doi.org/10.1016/i.jconhyd.2005.09.007 